\title{
Anti-EGFR TAP Antibody-drug Conjugate IMGN289
}

National Cancer Institute

\section{Source}

National Cancer Institute. Anti-EGFR TAP Antibody-drug Conjugate IMGN289. NCI

Thesaurus. Code C111906.

A targeted antibody payload (TAP)-based immunoconjug ate consisting of a human monoclonal antibody directed against the epidermal growth factor receptor (EGFR) conjugated, via a nonreducible thioether linker (succinimidyl trans-4-

(maleimidylmethyl)cyclohexane-1-carboxylate or SMCC), to the cytotoxic agent maytansinoid mertansine (DM1), with potential antineoplastic activity. Upon intravenous administration, the monoclonal antibody moiety of immunoconjug ate IMGN289 binds to and inhibits EGFR on tumor cell surfaces. Inhibition of EGFR prevents EGFR-mediated signaling and may inhibit tumor cell proliferation. After internalization, the mertansine moiety binds to tubulin and interferes with microtubule assembly/disassembly dynamics. This inhibits both cell division and the proliferation of cancer cells that express EGFR. EGFR, overexpressed by a variety of cancers, plays a key role in tumor cell proliferation and survival. Linkage of the antibody and drug, through a nonreducible linker, appears to contribute to the improved efficacy and reduced toxicity of this antibody-drug conjug ate (ADC) compared to similar ADCs constructed with reducible linkers. 